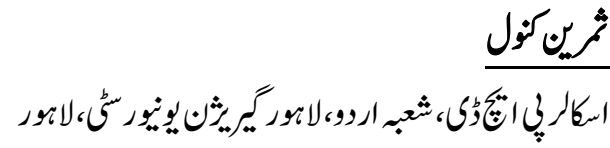

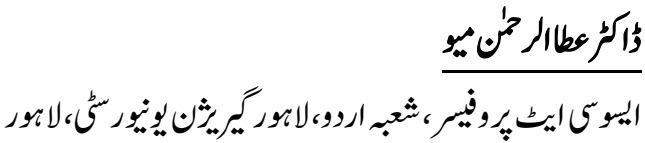

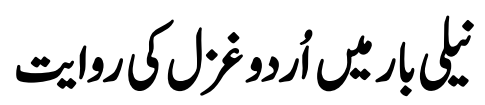

Samreen Kanwal

Ph.D Scholar, Department of Urdu, Lahore Garrison University, Lahore.

Dr. Atta-ur-Rehman Meo

Associate Professor, Department of Urdu, Lahore Garrison University, Lahore.

\title{
Urdu Ghazal Tradition in Blue Bar
}

The meaning of the Punjabi words five, Five more meaning of water of the Rivers. As if Punjab meant Land of Five Rivers, Narrator Chenab, Beas, Sutlej and the land of Jhelum. Punjab was named mention of these five rivers of Punjab also found in Rig Veda. Ten thousand years in the Indus Valley. Harappa is a historical place of Punjab. Punjab has been divided into five times: i) Bald Bar, ii) Sandal Bar, iii) Gondal Bar, iv) Hard Bar, v) Blue Bar. Bar literally means forest between the Sutlej and Ravi rivers. Albcities towns and villages. The area of the blue bar is called Blue bar of specific region, historical, political history reflects civilization and Islamic trends. The area between the Sutlej and Ravi rivers. They are green and lush. Because of the Blue Waters of the Sutlej river the area was named Blue Bar Ghazal is a reliable genre if Urdu Ghazal of Urdu poetry synonymous so it will not be necessary. Moulvi Noorul Hassan in Noor-ul-Lughaat. He writes about Ghazlas the literal meaning of ghazal is to talk to women in terms of those poems whose beauty and love carpentry and parting taste of desire Ja mine Madness etc., Somewhere about love the representative poets of the Blue Bar, will be mentioned in this article, among them are selected poets of Okara 
Zafar Iqbal, Masood Okarvi among the selected poets of Sahiwal Syed Naveed, Haider Hashmi, Iftikhar Shafi , among the selected poets of Pak Pattan Sharif Sayed Younas Mateen, Among the selected poets of Vehari Fartash Syed, Zaeem Rasheed.

Key Words: Poets, Punjabi, Rivers, Historical, Blue Bar, Region, Ghazal.

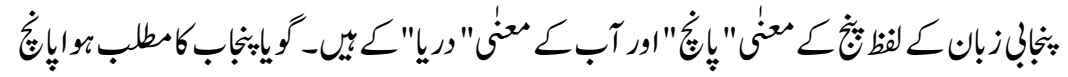

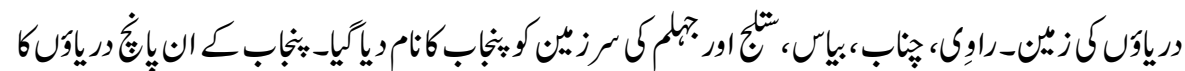

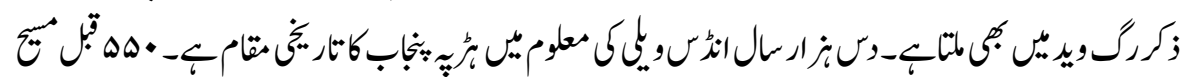

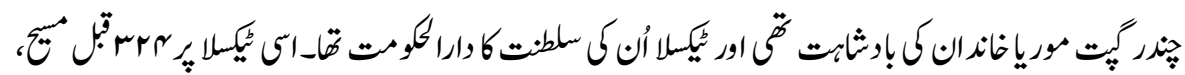

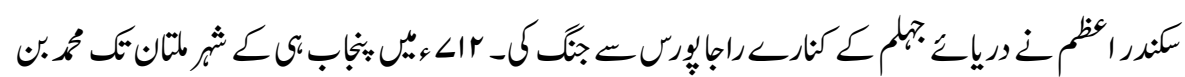

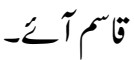

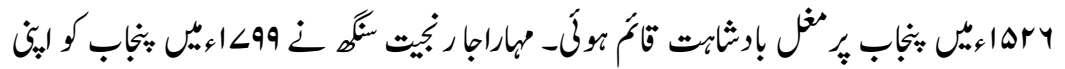

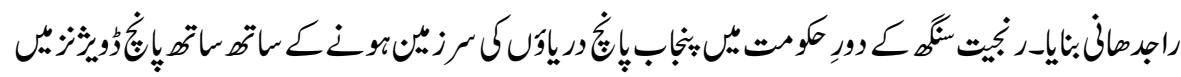

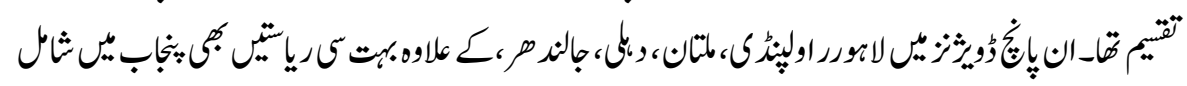

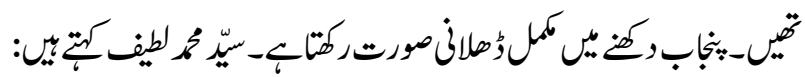

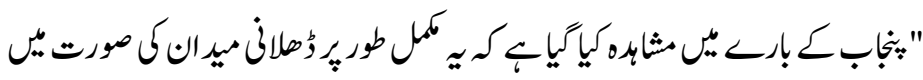

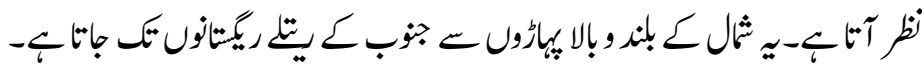

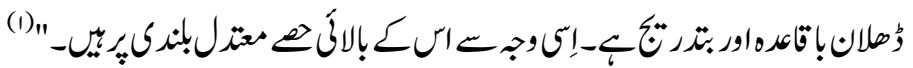

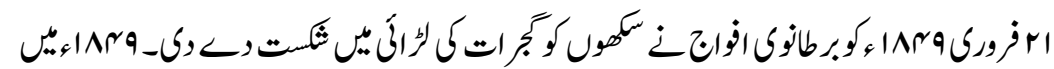

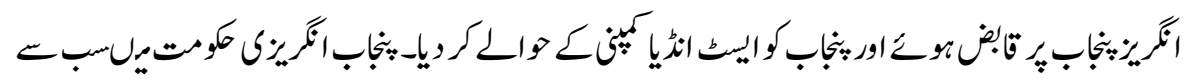

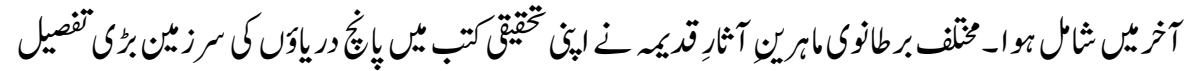

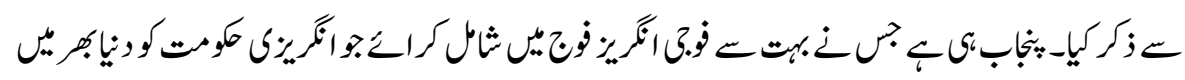

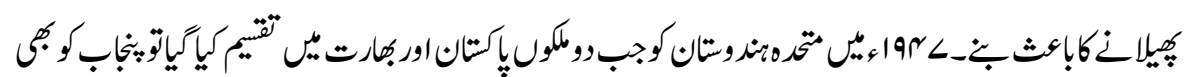

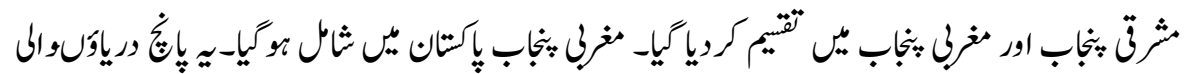

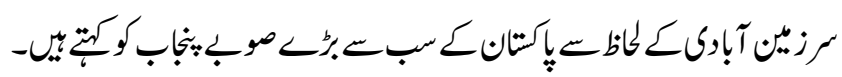




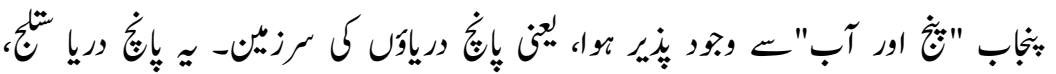

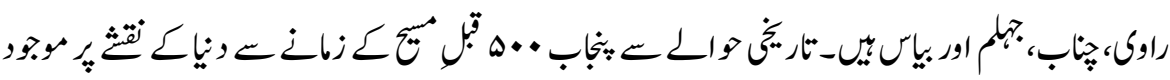

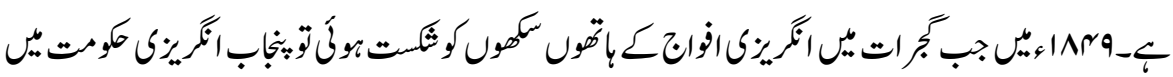

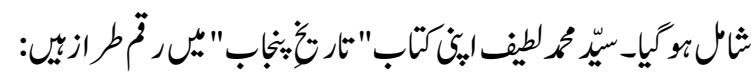

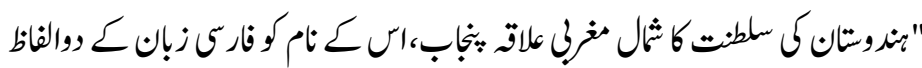

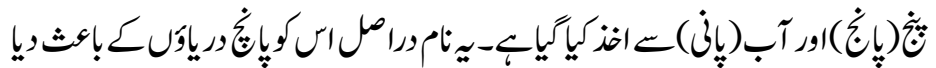

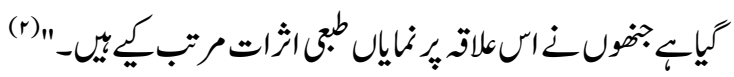

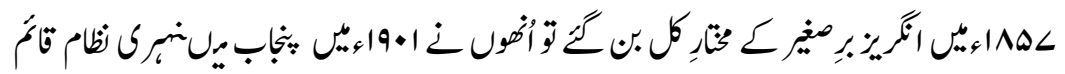

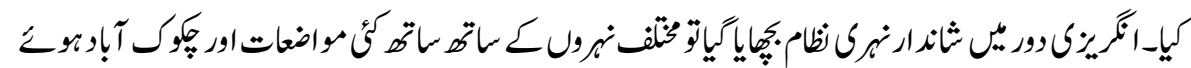

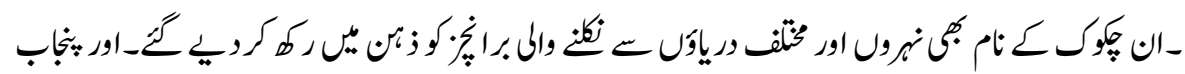

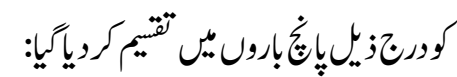

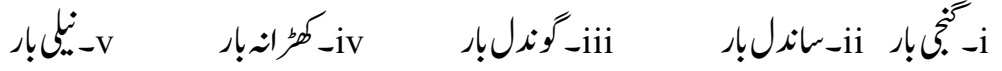
:

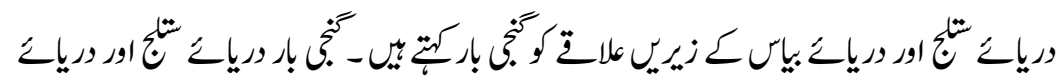

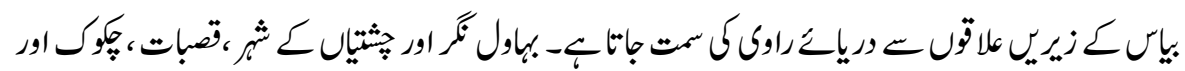

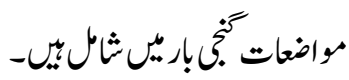
:

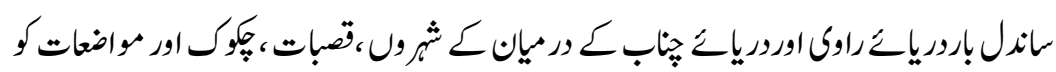

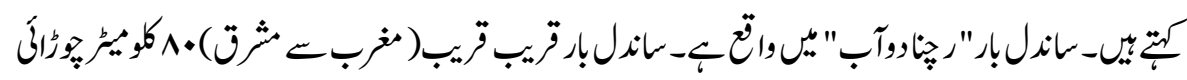

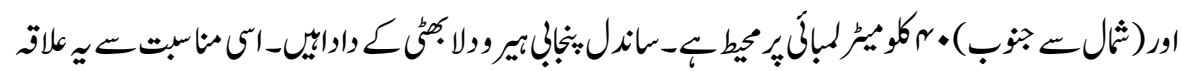

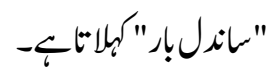

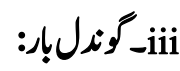

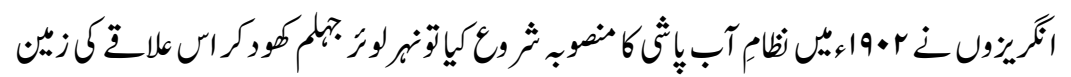




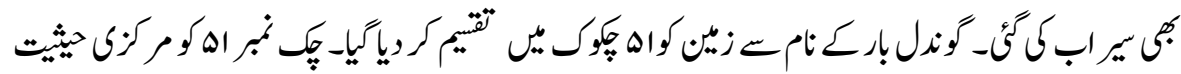

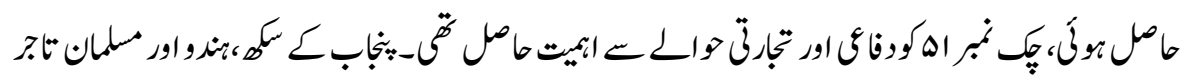
يميان آبإيوكثَ_كمّانهار: -iv

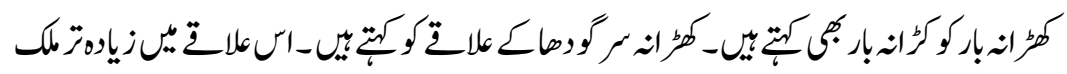

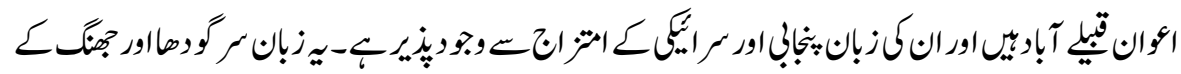

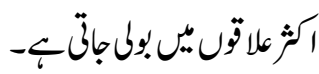
vن

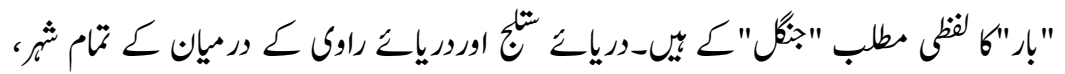

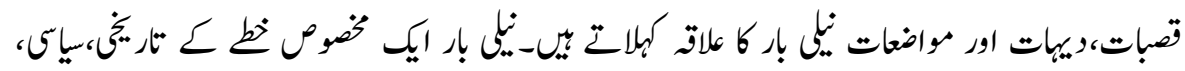

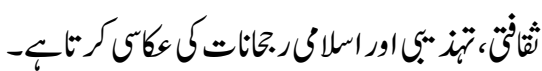

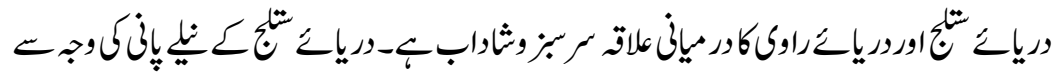

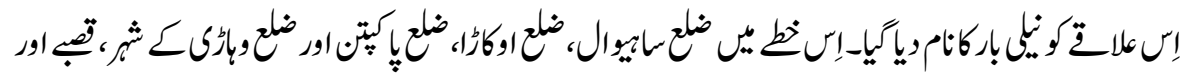

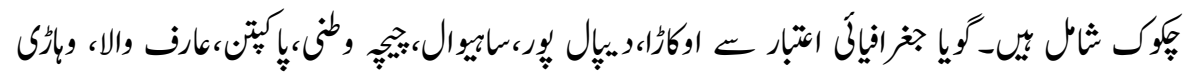

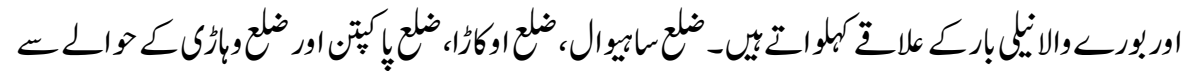

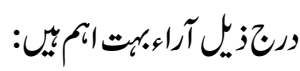

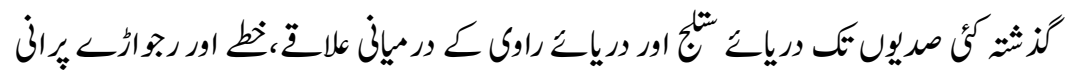

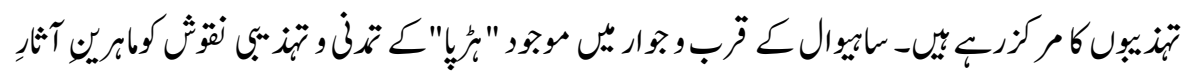

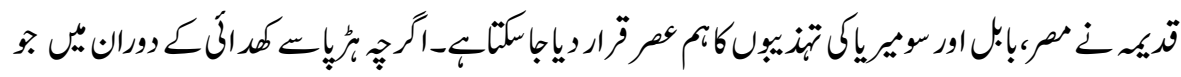

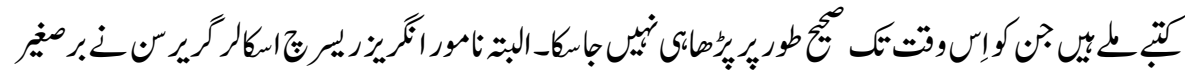

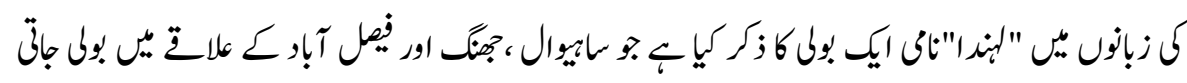

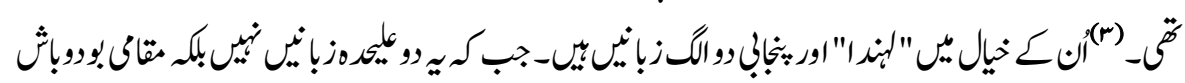

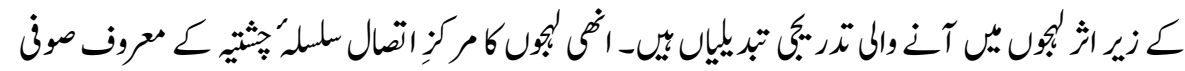




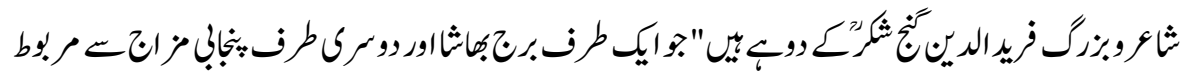

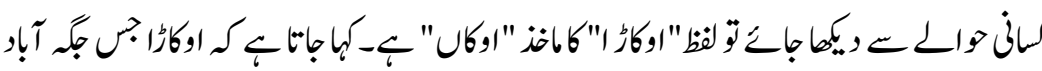

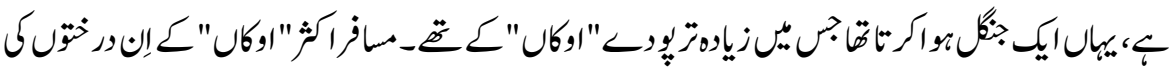

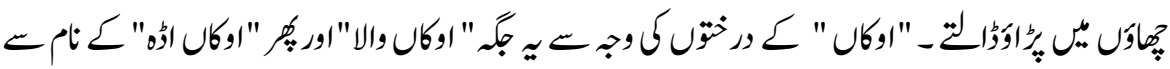

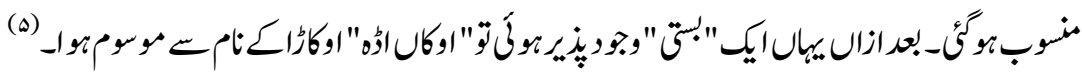

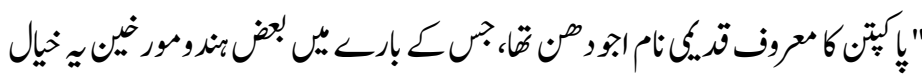

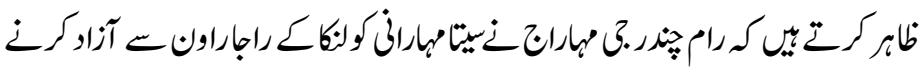

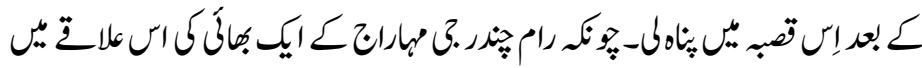

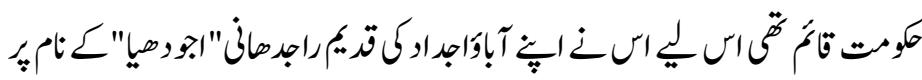

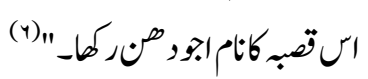

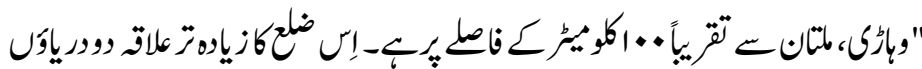

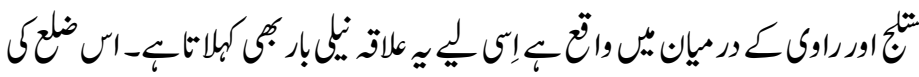

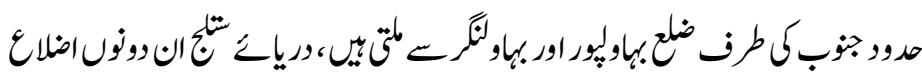

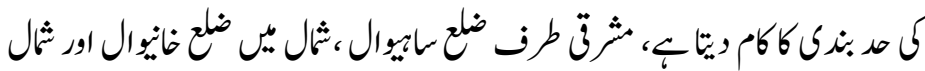

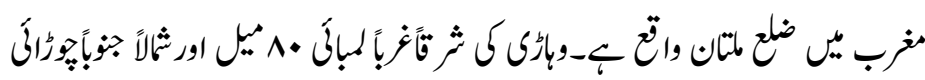

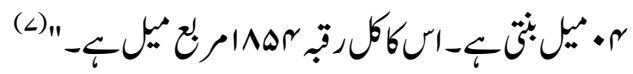

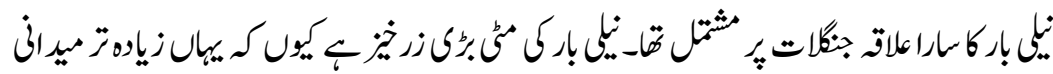

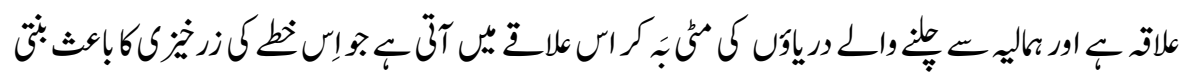
$-\frac{1}{6}$

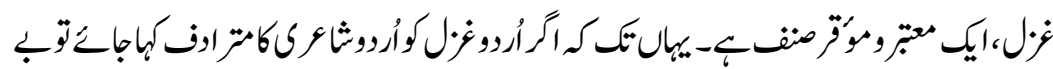

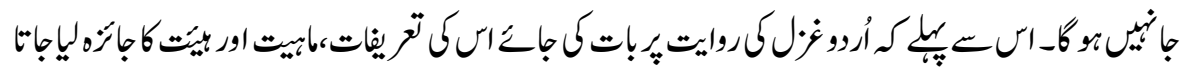

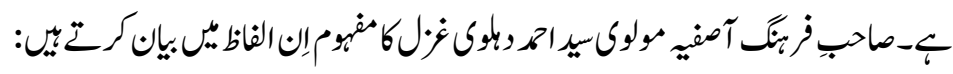




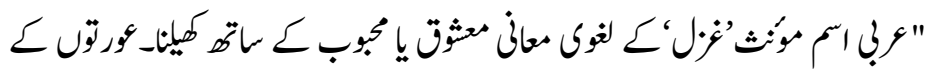

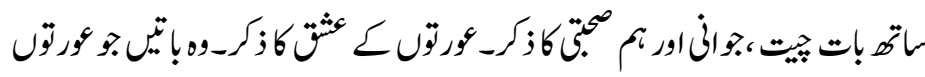

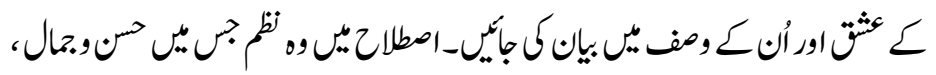

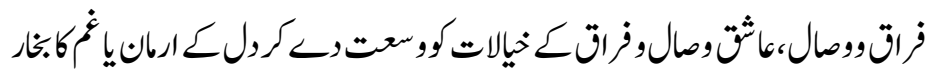

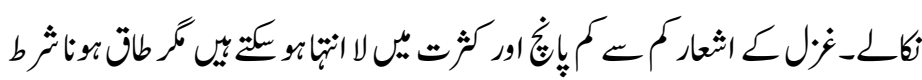

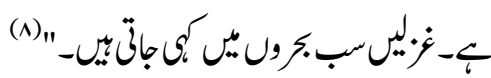

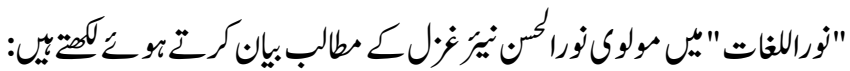

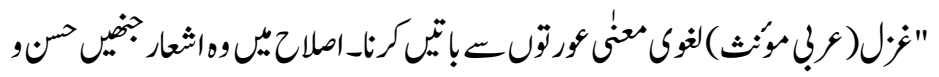

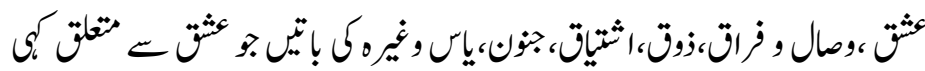
(9)

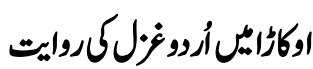

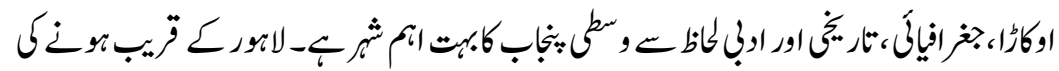

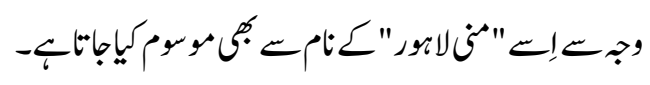

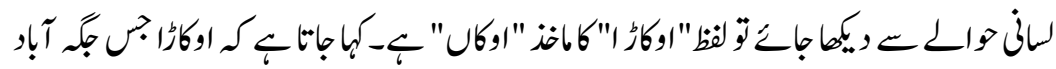

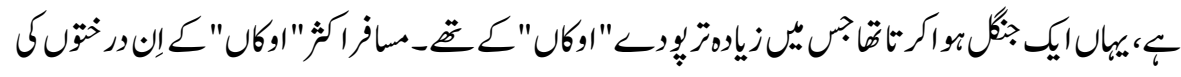

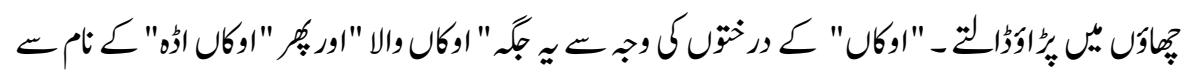

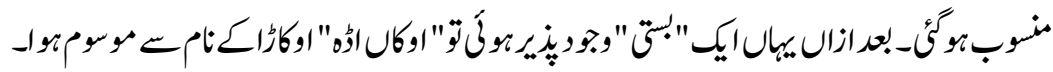

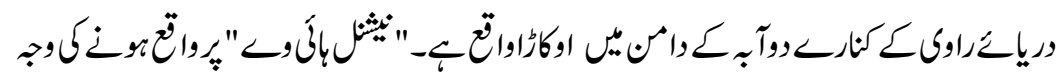

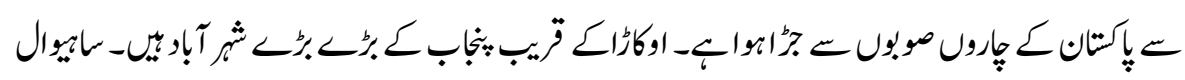

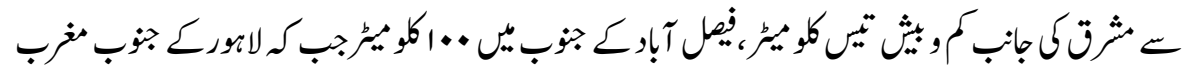

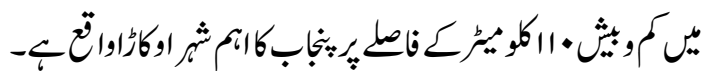

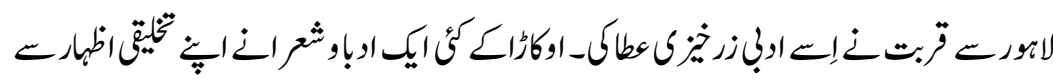

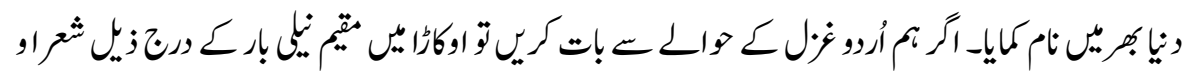




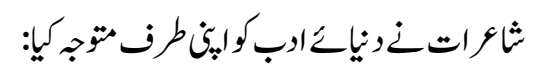

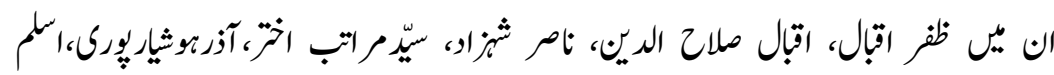

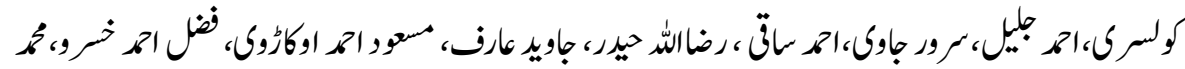

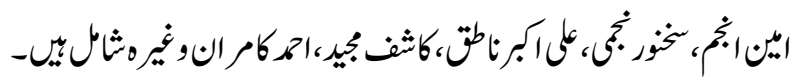

\section{حايواليّلرأروزلككروايت}

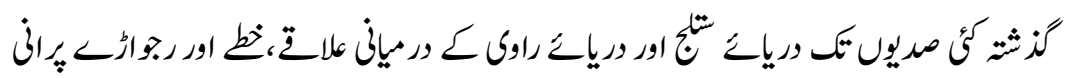

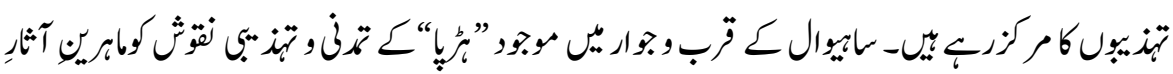

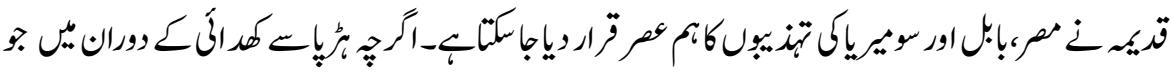

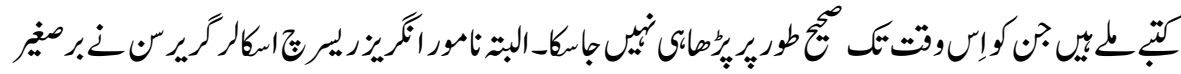

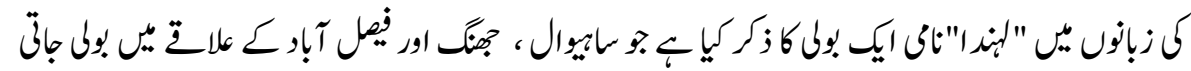

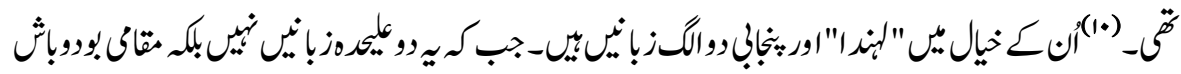

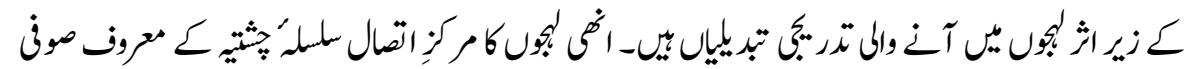

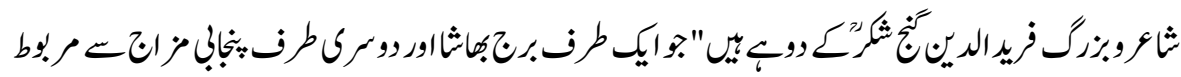

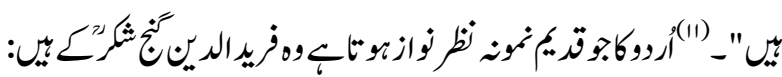

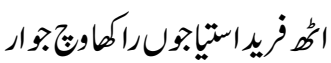

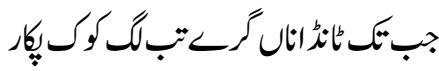

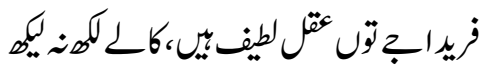

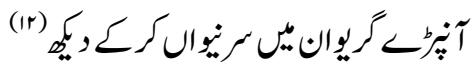

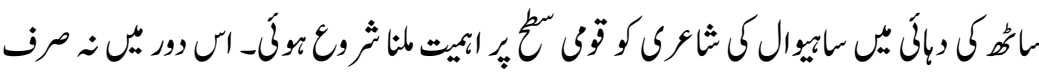

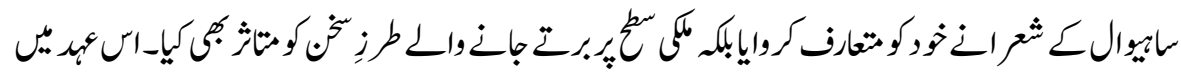

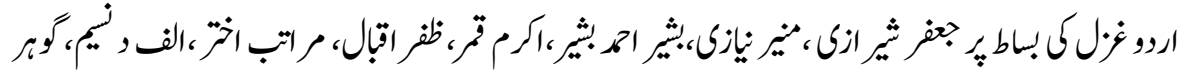

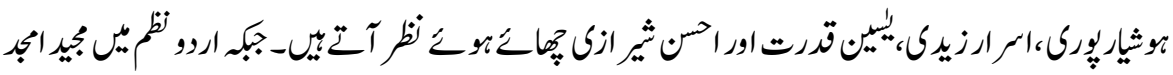

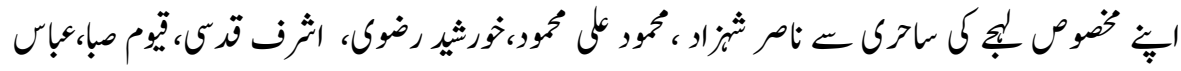




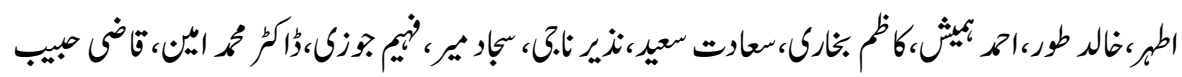

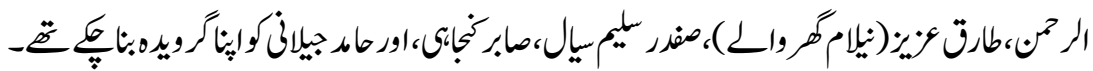

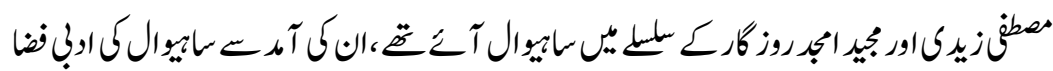

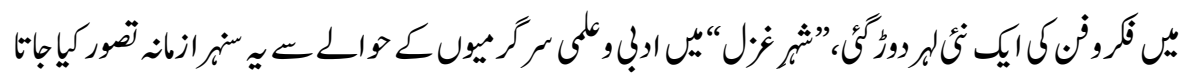

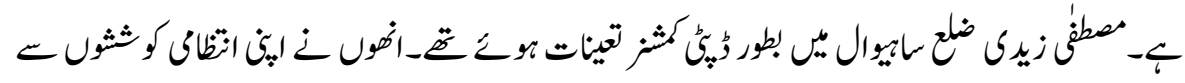

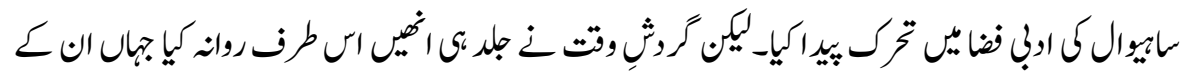

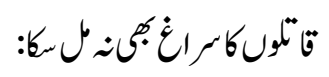

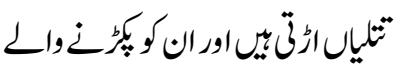

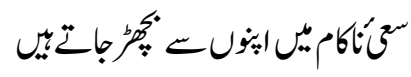
(معطئ)

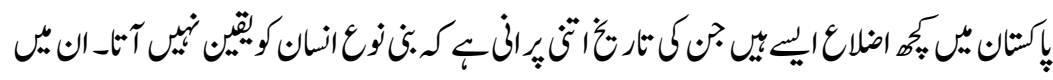

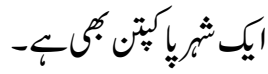

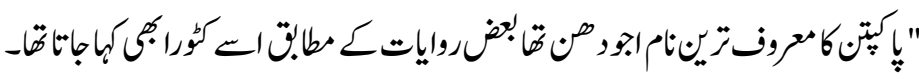

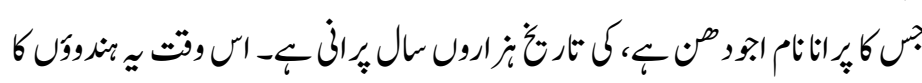

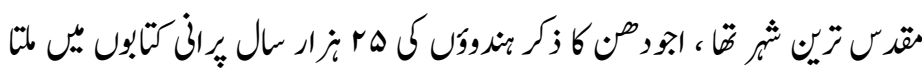
$(1 r)^{\prime}-4$

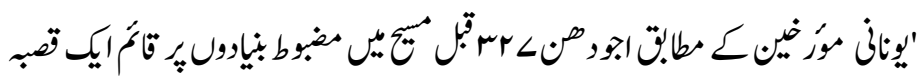

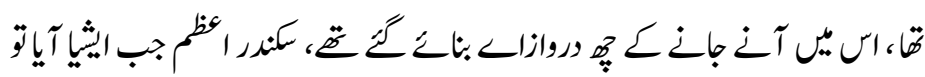

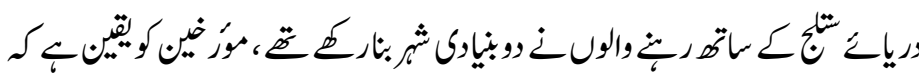

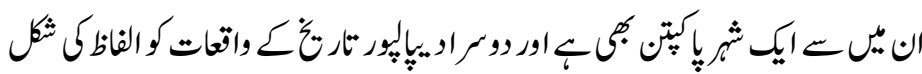

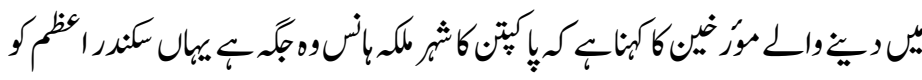

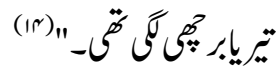

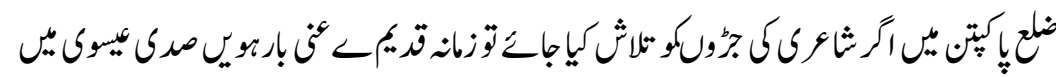




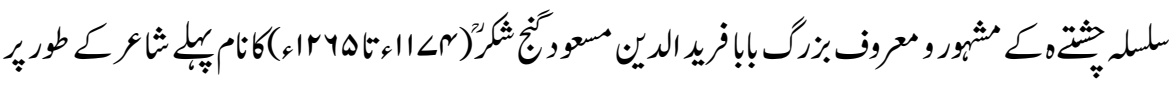

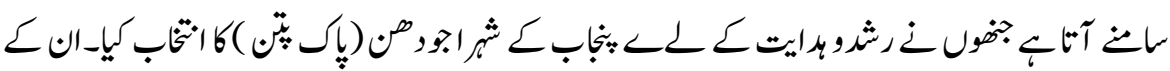

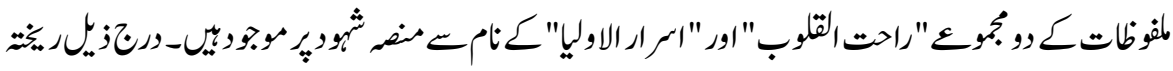

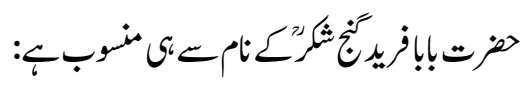

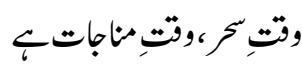

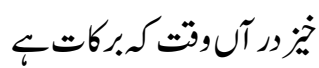

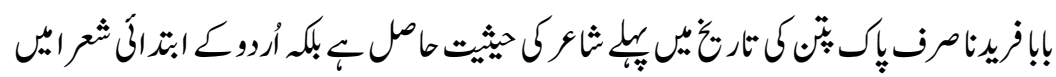

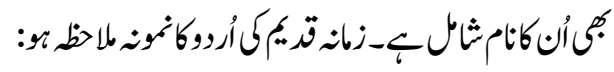

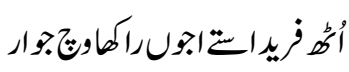

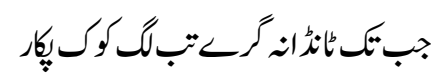

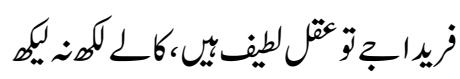

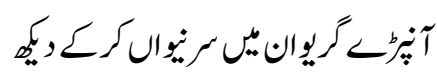

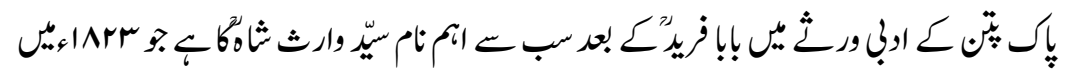

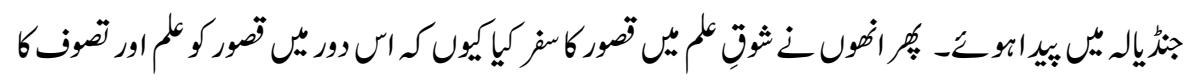

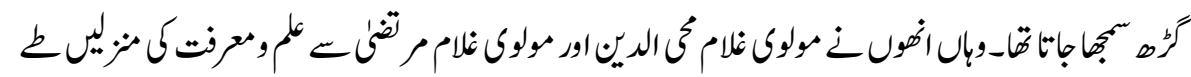

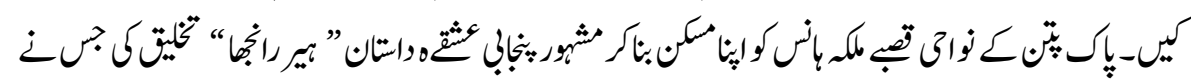

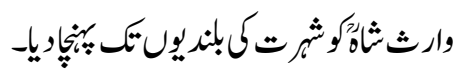

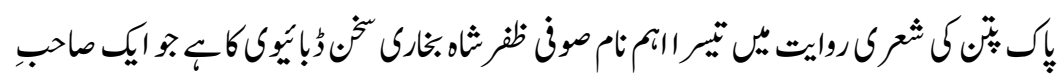

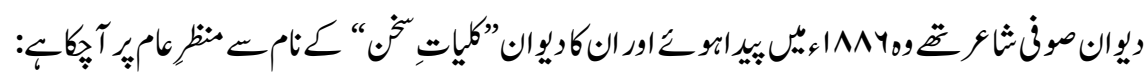

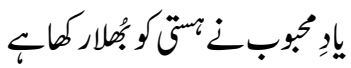

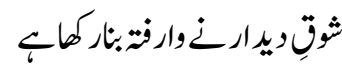

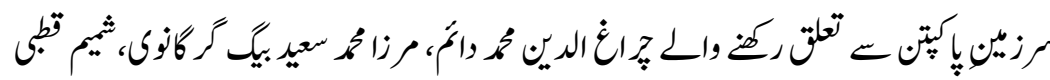

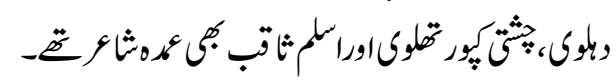




\section{وإئك::تأريخينيم}

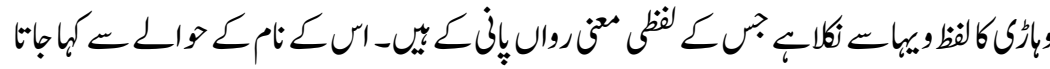

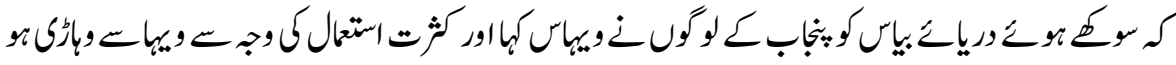

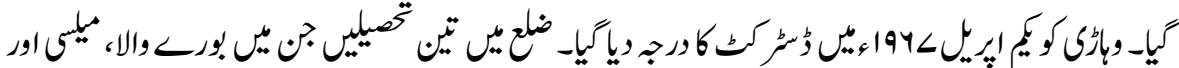

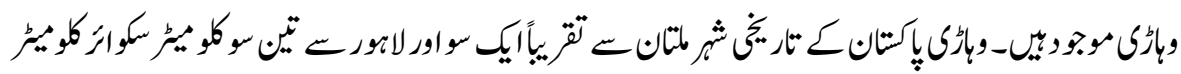

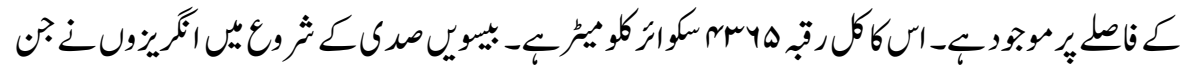

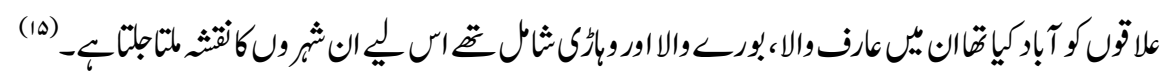

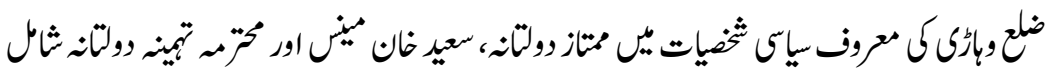

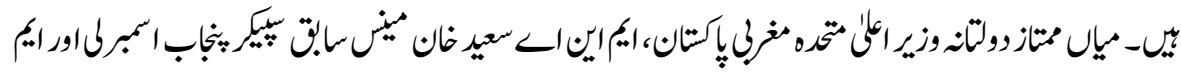

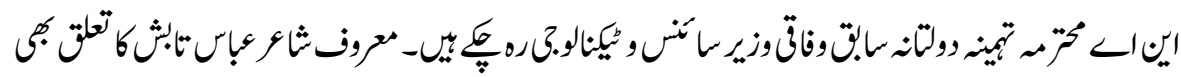

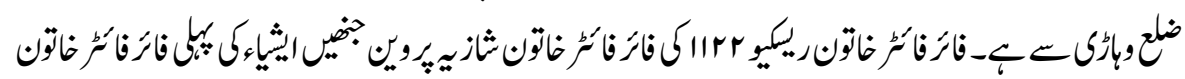
(14)

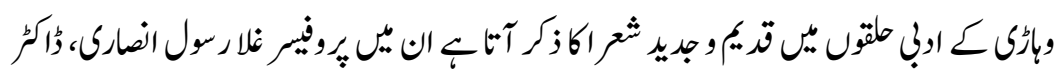

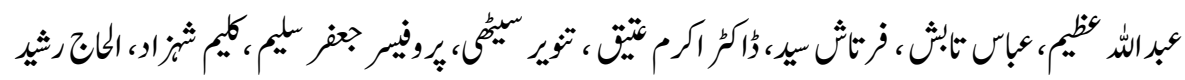

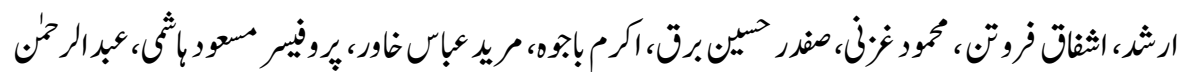

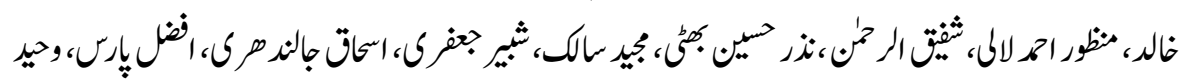

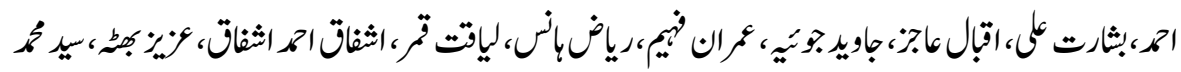

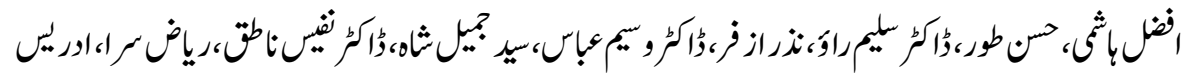

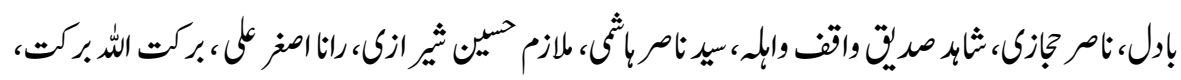

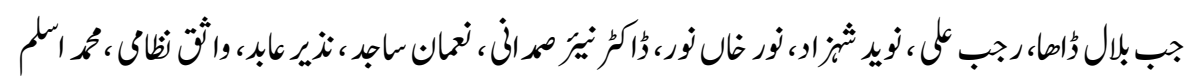

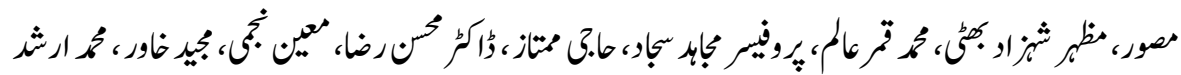

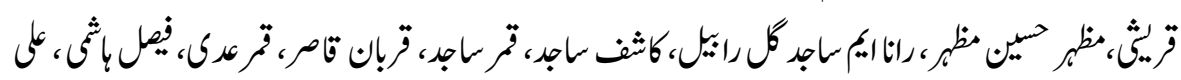

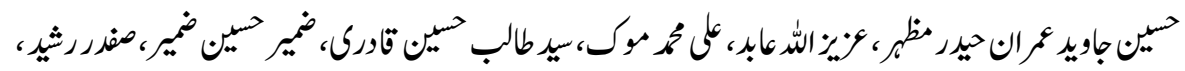




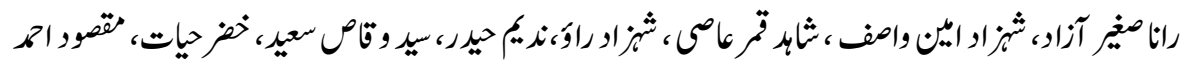

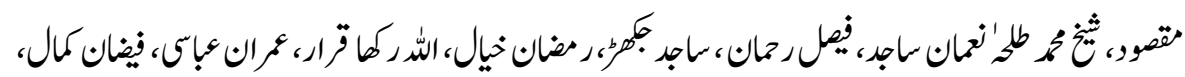

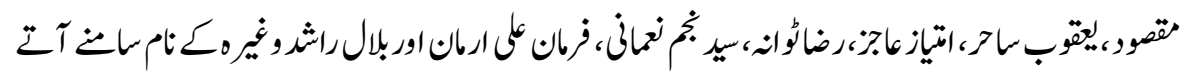

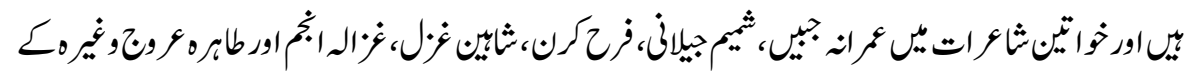

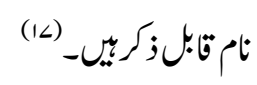

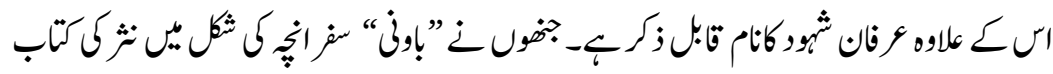

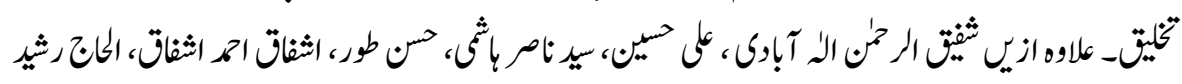

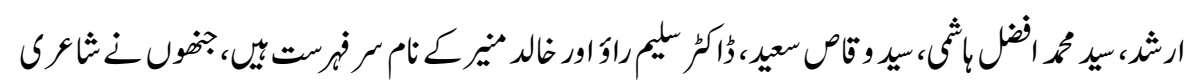

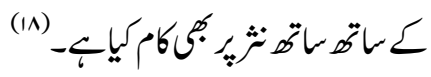
والـ توات

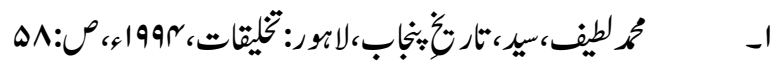
r

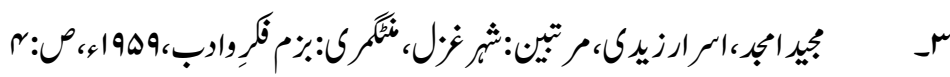

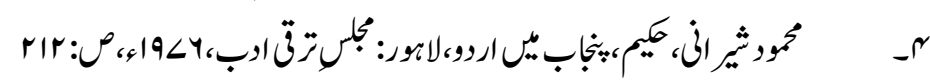
هـ

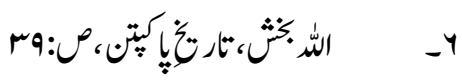

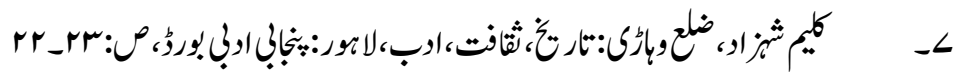

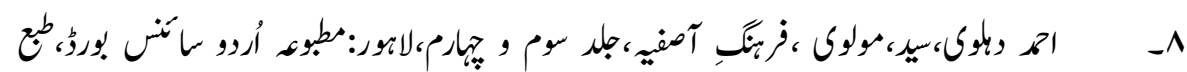

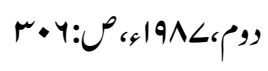

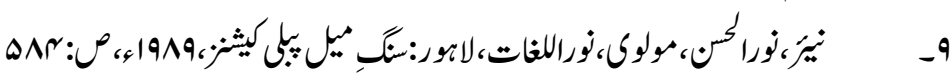

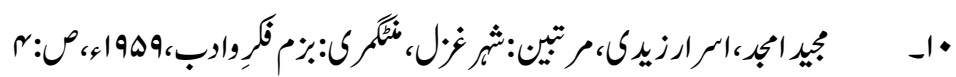

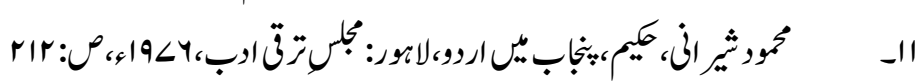
rاـ 


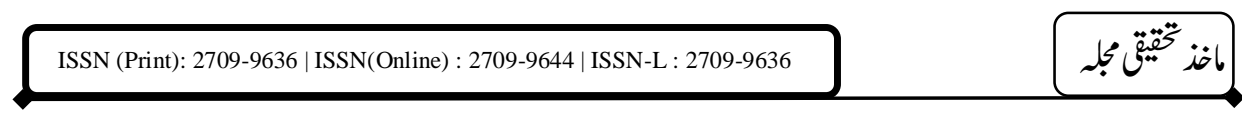

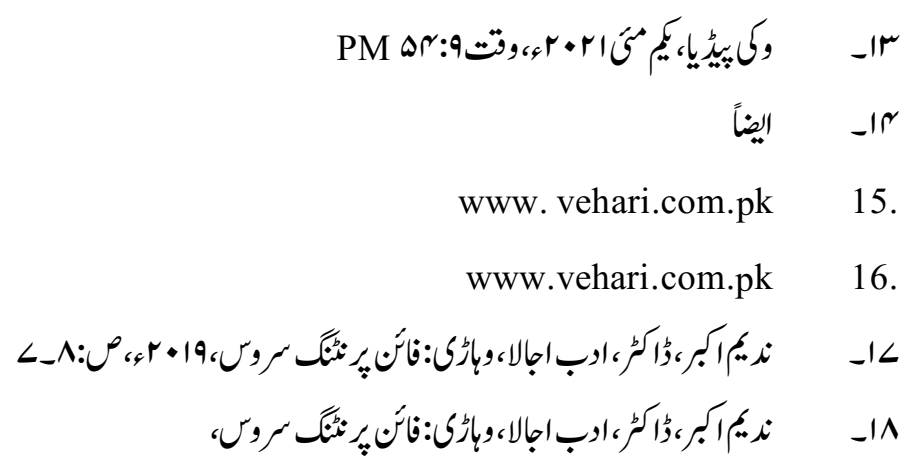

